\title{
Study to improve adding additives and washing step on surimi processing from moontail bigeye
}

\author{
Nguyen Thi Le Phuong ${ }^{1}$, Vu Ngoc Boi ${ }^{1}$, Nguyen Van Chung ${ }^{2}$ \\ ${ }^{1}$ Faculty of Food Technology, University of Nha Trang, Dong Nai City, Vietnam \\ ${ }^{2}$ Fisheries Co. Hoa Thang, Ba Ria, Vung Tau City, Vietnam
}

Email address:

phuonglepy2809@gmail.com (N. T. L. Phuong)

\section{To cite this article:}

Nguyen Thi Le Phuong, Vu Ngoc Boi, Nguyen Van Chung. Study to Improve Adding Additives and Washing Step on Surimi Processing from Moontail Bigeye. Journal of Food and Nutrition Sciences. Special Issue: Food Processing and Food Quality.

Vol. 3, No. 1-2, 2015, pp. 119-125. doi: 10.11648/j.jfns.s.2015030102.33

\begin{abstract}
In this article we annouced results of the study and improve for washing and mixing additives step to improve the quality of surimi production in Hoa Thang Fisheries Company - Ba Ria - Vung Tau to satisfy the Japanese market standard. The research shows that surimi production from moontaintail bigeye fish export Japanese standards (Gel Strength $>300 \mathrm{~g} . \mathrm{cm}$, whiteness $>48 \%$ ), moontail bigeye meat should be washed three times: using $\mathrm{NaCl} 0.2 \%$ for the first washing, etanol $2 \%$ for the second washing and sorbitol 3\% for the third washing; Duration for each washing time and ratio of washing solution and fish meat were 9 minutes and 4:1 (vol./wt.).; Additives were used, including sugar 3.5\%, sorbitol. 3.5\%, $0.2 \%$ sodium tripolyphosphate $0.2 \%$, caragin $0.3 \%$. Gel strength of moontail bigeye surimi can be reached to $740 \mathrm{~g} . \mathrm{cm}$, whiteness was $80.25 \%$ and black spot with 2 spots $/ 10 \mathrm{~g}$.
\end{abstract}

Keywords: Cleaning Fish Meat, Surimi, Processing of Moontail Bigeye Surimi

\section{Introduction}

Currently the production of surimi in Hoa Thang - Ba Ria Vung Tau company of fisheries (called Hoa Thang Company) as there are some restrictions and whiteness of surimi gel strength with Korean standards and demanding markets such as China and Taiwan. Therefore, the production and export of surimi Hoa Thang Company in the market have high quality standards as the U.S., Europe and Japan face many difficulties due to the market requires to surimi gel strength $>300 \mathrm{~g} . \mathrm{cm}$, whiteness $>48 \%$ and the number of sunspots $<4$ points $/ 10 \mathrm{~g}$. While surimi quality of Hoa Thang Company only gel strength: 100-200 g.cm, whiteness: $40-45 \%$, sunspots $>5$ points $/ 10 \mathrm{~g}$. Therefore, we conducted a "Research finishing washing and mixing additives to improve the quality of surimi production in Hoa Thang - Ba Ria - Vung Tau company of Fisheries," the desire to improve the quality of surimi for export to the Japanese market standards- a difficult market.

\section{Materials and Methods}

\subsection{Macterials}

- Main material: Moontail bigeye, Moontail bullseye
(Figure 1). Fish material is bought from Ba Ria - Vung Tau port by Hoa Thang company of fisheries.

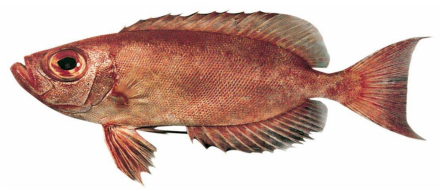

Figure 1. Moontail bigeye

Morphological characteristics: fish body longish oval, very laterally compressed, top to medium high, short snout, big eyes, eye diameter by $1 / 2$ length of head, red body more toward back as Dark. Distribution: Hawaii, Red Sea, Japan, Philippines, Vietnam. Fishing season: All year round. Dimensions operators: 260-300 mm

- Auxiliary material: The material parts used in this study including liquid sorbitol ( $70 \%$ concentration), $96^{\circ}$ foodgrade alcohol, caragin, sodium tripolyphosphate salt is offerred by Huu Loi Ho Chi Minh City; Bien Hoa Sugar; salt is offerred by Ba Ria Vung Tau salt companie.

\subsection{The Process is Expected Surimi Processing}

The process is expected surimi processing is done by the 
process of Hoa Thang Company as follows:

Macterial $\rightarrow$ Handling $\rightarrow$ Washing $1 \rightarrow$ Washing 2 $\rightarrow$ Washing $3 \rightarrow$ Water press $\rightarrow$ Mixing phụ gia $\rightarrow$ Pounding $\rightarrow$ Shaping $\rightarrow$ Freezing $\rightarrow$ storage.

\subsection{Research Methodology}

\subsubsection{Methods of Chemical Analysis}

- Assessment of sensory quality of surimi: Vietnam standard TCVN 3215-79.

- Evaluation of surimi gel strength, toughness, color of surimi was conducted in 28 TCN 119:1998.

\subsubsection{Methods of Sensory Analysis}

- Determination of fat content in accordance with ISO 3703-2009 accreditation is VILAS.

- Determination of protein by the method CASE.NS.004 (TCVN 3705-1990) is recognized VILAS.

- Determination of moisture: by drying to constant weight TCVN 3700-90.

\subsubsection{Methods for Microbiological Analysis}

- Determination of total aerobic microorganisms: ISO 4833:2003.

- Identify Coliforms: ISO 4832:2006.

- Identify E.coli: ISO 7251:2005.

- Identify Staphylococcus aureus: ISO 6888-1 (1/1999).

- Identify Salmonella: ISO 6579:2007.

- Identification of Vibrio cholerae: ISO 21872-1:2007.

\subsection{Chemical Instruments and Equipment Primarily Used in the Experiment}

- Chemical: use of standard chemical analysis of Merck Germany.

- Office equipment primarily used in the experiment: the use of existing equipment in Hoa Thang Company: White measuring chroma meter (CR 400, Minolta, Osaka, Japan); gel strength measuring equipment CR500DX Sun Rheometer (Japan); analytical balance, sausage extruder, infrared moisture meter; temperature measurement equipment

\subsection{Treatment Method Statistics}

By Software Design - Expert software version 8.0 and SPSS-16. Significant difference at $\mathrm{p}$ value $<0.05$. Graphing with Microsoft Office Excel 2007 software.

Data processing software Design - Expert version 8.0 and optimized convolution algorithm targeting function is expecting data processing methods are commonly used in chemical engineering and food with high reliability and consistent with the empirical model and multi-purpose

\section{Results and Discussion}

\subsection{Research Finishing Washing}

\subsubsection{Determining the Concentration of Saline Wash $1^{\text {st }}$} $\mathrm{NaCl}$ affects the intensity of gel (Gel Strength - GS) and whiteness of surimi is presented in Figure 2 and Figure 3.

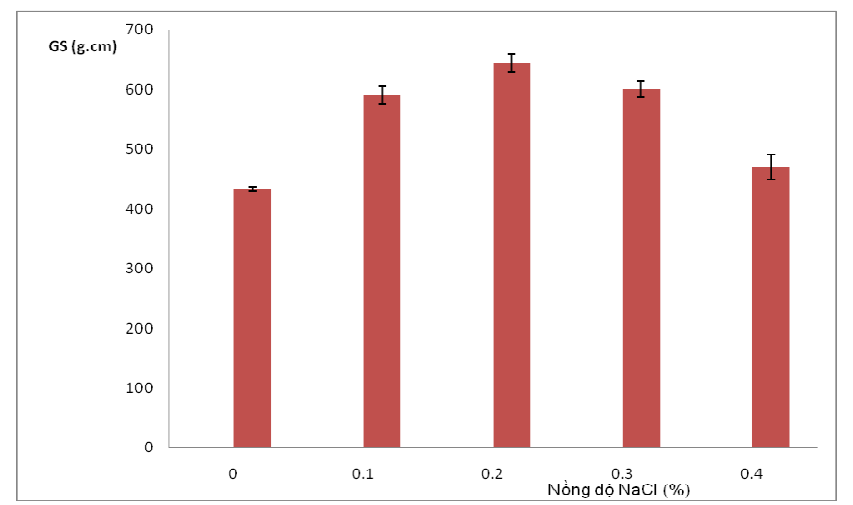

Figure 2. Influence of $\mathrm{NaCl}$ concentration to gel strength of surimi Moontail bigeye fish

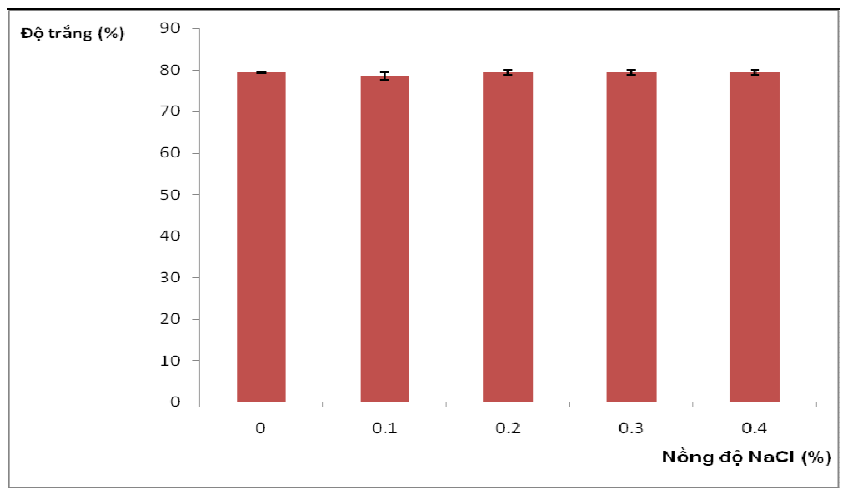

Figure 3. Influence of $\mathrm{NaCl}$ concentration in the wash water whiteness surimi Moontail bigeye fish

- On the strength of surimi gel:

When fish wash with dilute salt solution at different concentrations surimi gel strength will be different. Specifically, the concentration of $\mathrm{NaCl} 0.1 \%, 0.2 \%, 0.3 \%$ and $0.4 \%$ of surimi gel strength $590 \mathrm{~g} . \mathrm{cm}$ respectively, 644 g.cm, $600 \mathrm{~g} . \mathrm{cm}$ and $470 \mathrm{~g}$. centimeters. Thus, grind meat and fish washed in $0.2 \% \mathrm{NaCl}$ for surimi gel strength of surimi highest.

The findings above can be explained by washing with dilute saline solution will help remove impurities capital good in dilute salt solution as the odor is not good bases for surimi products, soluble protein can affect the gelling process as sarcroplasmic, ... By W. Park Jea, 2004 sarcroplasmic is a protein accounted for $23.5 \%$ of the total protein in muscle, which acts hinder the process of creating surimi gel, reduces the intensity of surimi gel. On the other hand saline solution also helps improve muscle hydration of proteins. So when washed with saline solution, gel strength of surimi fish is better.

- About the whiteness of surimi:

Effect of salt concentration to the whiteness of surimi is shown in Figure 3 shows the salt concentration in the wash water fish have no significant impact to fish surimi whiteness. When you wash 1 with $\mathrm{NaCl}$ concentration range of $0-0,4 \%$, the whiteness of surimi fish grain paint negligible change in the range of $78.39 \%$ and $79.36 \% \div$. The difference is not 
much in terms of when washing white fish in the salt concentration of the aqueous wash different can be explained by the pigment in the meat and fish in general are mainly soluble in the mixture of oil So when washed with saline solution, the pigments are attracted under limited water wash.

Thus, the concentration of sodium chloride suitable for fish wash painting process once the rice is $0.2 \% 1$.

\subsubsection{Determine the Concentration of Alcohol Solution Washed 2 Times}

Alcohol may affect the gel strength (GS) and whiteness of surimi is presented in Figure 4 and Figure 5.

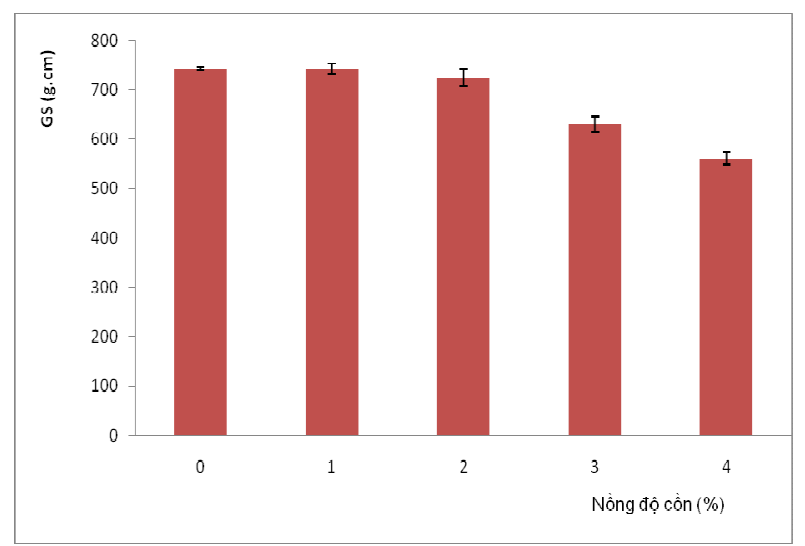

Figure 4. Influence of alcohol concentration in the gel strength of surimi

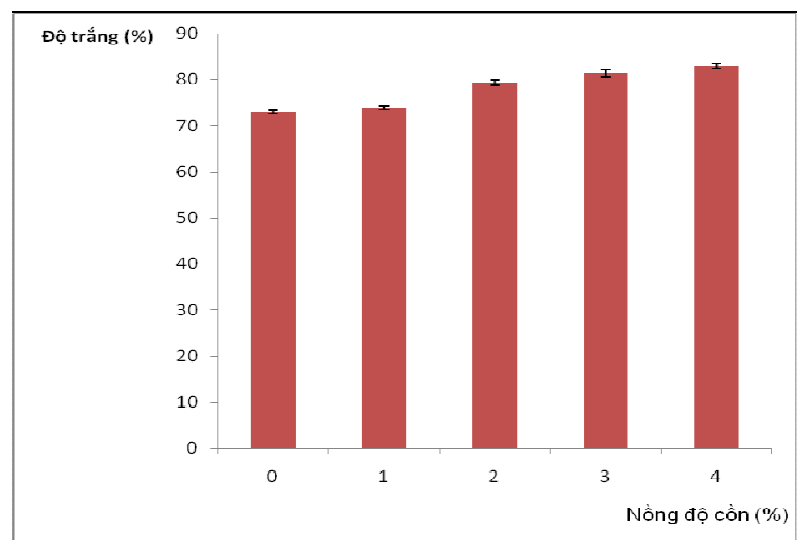

Figure 5. Influence alcohol to paint fish surimi whiteness

- On the strength of surimi gel:

When fish wash with a solution of alcohol in different concentrations for surimi gel different intensity. Specifically, control samples and samples washed with a solution of $1 \%$ alcohol, surimi gel strength is $743 \mathrm{~g} . \mathrm{cm}$; In the sample washed with a solution of alcohol at a concentration of $2 \%$, $3 \%$ and $4 \%$ surimi gel strength $725 \mathrm{~g} . \mathrm{cm}$ respectively, $631 \mathrm{~g} . \mathrm{cm}$ and $561 \mathrm{~g} . \mathrm{cm}$. This can be explained by the increased concentration of alcohol increases the likelihood of causing dehydration and protein denaturation of fish meat to make surimi gel strength decreased. Thus, fish washing with a solution of $1 \%$ alcohol will surimi gel highest quality. Furthermore, alcohol has the ability to deodorize by the nature of fishy odors such as TMA, urea, high molecular fatty acids are good soluble in alcohol. Add to that the effects of alcohol have better meat color remover.

- About the whiteness of surimi:

Influence of alcohol to the whiteness of surimi is shown in Figure 5 shows the concentration of alcohol in the wash water fish can significantly affect the color of fish surimi grain paint. Specifically, in the samples washed with a solution of $0 \%, 1 \%, 2 \%, 3 \%$ and $4 \%$ respectively whiteness of surimi is $73 \%, 73.89 \%, 79.38 \%, 81.44 \%$ and $82,94 \%$. However, when increasing concentrations of alcohol in the wash water, the higher the gel strength decreased. Thus, $2 \%$ alcohol solution was selected as the 2nd wash to achieve strength and whiteness of surimi fish most harmonious grain paint.

From the above analysis shows that the concentration of alcohol in the wash water suitable for fish wash painting process paddy milling times 2 is $2 \%$.

\subsubsection{Determining the Concentration of Sorbitol Solution Washed 3 Times}

Sorbitol affect the strength and whiteness of surimi gel is shown in Figure 6 and Figure 7.

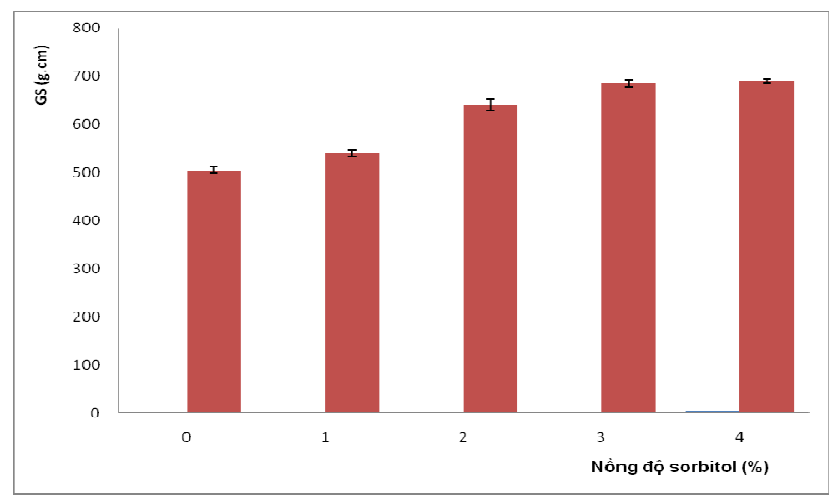

Figure 6. Influence of sorbitol concentrations wash 3 to gel strength of surimi fish painted rice

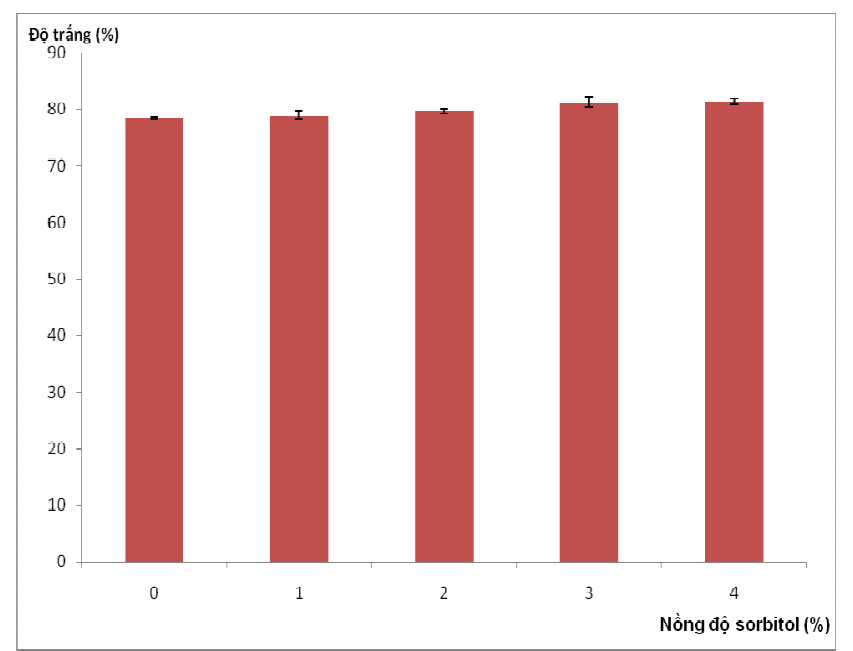

Figure 7. Influence of sorbitol concentrations in fish surimi whiteness of paddy paint

- On the strength of surimi gel:

When fish wash with a solution of sorbitol in different concentrations for surimi gel different intensity. Specifically, 
the control sample of surimi gel strength is just $505 \mathrm{~g} . \mathrm{cm}$, in the form of sorbitol solution washed with $1 \%, 2 \%, 3 \%$ and $4 \%$ surimi gel strength $540 \mathrm{~g} . \mathrm{cm}$ respectively, $641 \mathrm{~g} . \mathrm{cm}$, and $690 \mathrm{~g} . \mathrm{cm} .685 \mathrm{~g} . \mathrm{cm}$ Thus, when fish wash with a solution of $3 \%$ and $4 \%$ sorbitol will surimi gel quality high. This result can be explained by the sorbitol is a polyol should be able to hold water. Therefore, when using cleaning solution sorbitol will make less meat protein denaturation. On the other hand polyol is sorbitol should be soluble dyes in pigment meat should be washed according to the washing water. ANOVA results also showed that the concentrations of sorbitol wash in $3 \%$ and $4 \%$, the gel strength of surimi no difference. Therefore, we chose to economic concentrations of sorbitol $3 \%$ for washed 3 times.

- About the whiteness of surimi:

When meat processor in sorbitol, with different levels for different surimi whiteness. In the concentration range studied $(0 \%-4 \%)$, sorbitol concentrations in the wash water will increase the whiteness of surimi increased. Specifically, control samples whiteness of surimi was $78.51 \%$, in the form of sorbitol solution washed with $1 \%, 2 \%, 3 \%$ and $4 \%$ respectively surimi whiteness is $78.91 \%, 79.64 \%, 81.27 \%$ and $81.38 \%$. ANOVA results also showed that the concentrations of sorbitol wash in $3 \%$ and $4 \%$, the gel strength of surimi no difference. Therefore, we chose to economic concentrations of sorbitol 3\% for washed 3 times.

From the above analysis shows that the concentration of sorbitol in the appropriate wash water washing 3 times $3 \%$.

\subsection{Research Building Formula Additives Mixed}

Test design modeled Box Benkhen affect the results of the additive percentage in Table 1 .

Table 1. Experimental results of additive mixing process

\begin{tabular}{lllll}
\hline STT & $\begin{array}{l}\text { A: Caragin } \\
(\%)\end{array}$ & $\begin{array}{l}\text { B: sorbitol } \\
(\%)\end{array}$ & $\begin{array}{l}\text { C: sugar } \\
(\%)\end{array}$ & $\begin{array}{l}\text { Y: gel of strength } \\
\text { (g.cm) }\end{array}$ \\
\hline 1 & 0,1 & 1,0 & 3,0 & 600 \\
2 & 0,5 & 1,0 & 3,0 & 650 \\
3 & 0.1 & 5,0 & 3,0 & 690 \\
4 & 0,5 & 5,0 & 3,0 & 660 \\
5 & 0,1 & 3,0 & 1,0 & 620 \\
6 & 0,5 & 3,0 & 1,0 & 670 \\
7 & 0,1 & 3,0 & 5,0 & 720 \\
8 & 0,5 & 3,0 & 5,0 & 710 \\
9 & 0,3 & 1,0 & 1,0 & 610 \\
10 & 0,3 & 5,0 & 1,0 & 660 \\
11 & 0,3 & 1,0 & 5,0 & 700 \\
12 & 0,3 & 5,0 & 5,0 & 720 \\
13 & 0,3 & 3,0 & 3,0 & 740 \\
14 & 0,3 & 3,0 & 3,0 & 730 \\
15 & 0,3 & 3,0 & 3,0 & 735 \\
\hline
\end{tabular}

Using Design-Expert 8.0 software. to handle the data. The results build regression equation:

$\mathrm{Y}=735+7.5 \mathrm{~A}+\mathrm{B}+36.2521 .25 \mathrm{C}-20 \mathrm{AB}-15 \mathrm{AC}-\mathrm{A} 2$ $38.75-46.25-16.25 \mathrm{~B} 2 \mathrm{C} 2$

The degree of fit Lact incompatible: $-($ Prob $>F)=-0.3141$ $<0.05$. Appropriate regression equation.

\subsection{Optimized Additive Mixing Ratio Based on Design- Expert 8.0 Software}

\subsubsection{The Influence of Each Factor to the Gel Strength of Surimi}

- Effect of surimi gel strength caragin to

From the results processed by the software Design-Expert 8.0, the graph shows the influence of the intensity ratio caragin surimi gel (Figure 8 ) shows that the mixing ratio increased from $0.1 \%$ to $0,5 \%$, at the beginning of surimi gel strength increased when using caragin rate from $0.32 \%$ to $0.1 \%$ and peaked at caragin additional rate of approximately $0.3 \%$ to $0.32 \%$, then descending. This result is explained by caragin product is produced from carrageenan should be able to hold the water and stabilize the structure of the gel. The results of data processing using Design-Expert 8.0 software, the quality surimi products at the best rate caragin additional $0.3 \%$ to $0.32 \%$ from the corresponding surimi gel strength indicated on software from $735 \mathrm{~g} . \mathrm{cm}$ to $735.353 \mathrm{~g} . \mathrm{cm}$.

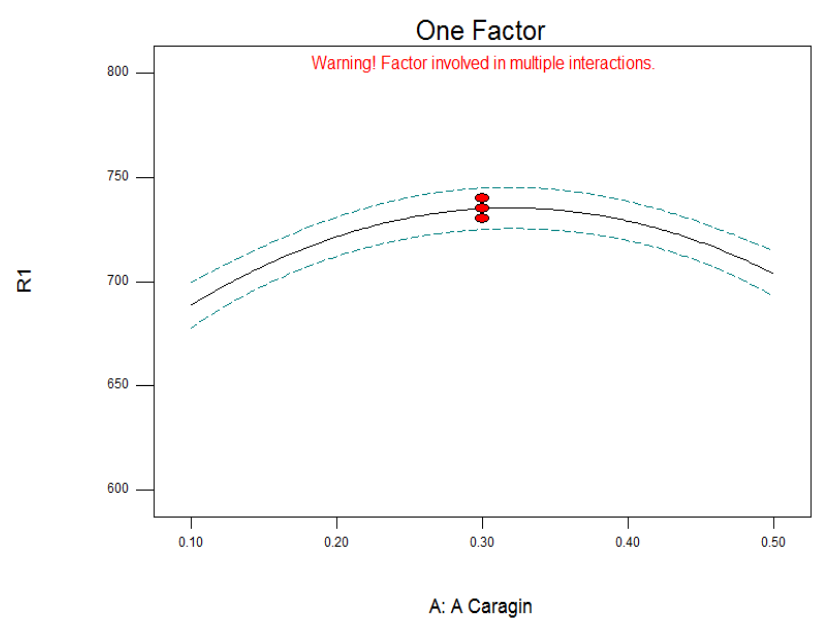

Figure 8. Caragin the influence of gel strength

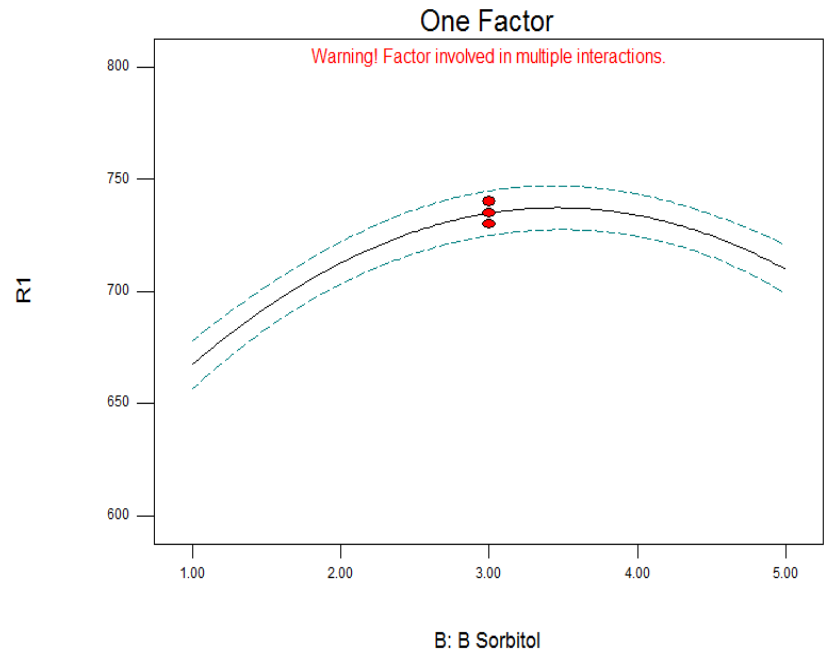

Figure 9. Influence of sorbitol to gel strength 


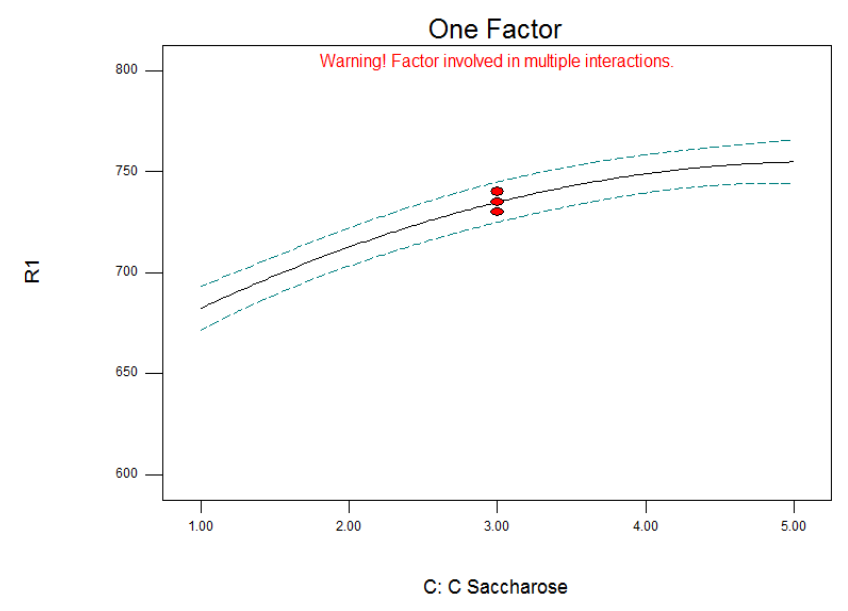

Figure 10. Effects of sugar to gel strength of surimi

- Effect of sorbitol to surimi gel strength

Results processed by the software Design-Expert 8.0, the graph shows the influence of the intensity ratio of sorbitol to surimi gel (Figure 9) shows the proportion increased sorbitol in about $1 \%-5 \%$, gel strength at first and gradually increase the rate peaked at $3.4 \%$ sorbitol additional gel corresponding intensity is reached $734.551 \mathrm{~g} . \mathrm{cm}$, but then if the rate continues to rise sorbitol, the gel strength decreased. According to Lee et al Carpenter said sorbitol and sugar stable three-dimensional structures of proteins and protein complexes generated effects-sorbitol increases the waterholding capacity. Black and colleagues suggest that sugar and sorbitol stabilizes the protein structure against the effects of temperature due to their impact on the structure of water molecules. The hydrophobic interactions between the hydrophobic groups of the protein in solution in the water line will be stronger. On the other hand, Lee and Timasheff cohesive force that increases road surface tension of water so that priority control of protein interactions with the solute in solution so do roads stabilizing protein. However, to use a certain percentage of the amount of sorbitol as many would make great products with moisture content resulting gel network structure loose, surimi gel strength decreased.

- Effect of sucrose in sugar surimi gel strength

The strength evaluation Figure 10 shows the gel strength of surimi gel increased linearly, ie the ratio of added sugars increase the gel strength increased. The results indicate that the software in the concentration range studied, at concentrations of 5\% sugar surimi gel highest intensity and reach 753.846 g.cm. In addition to creating the effect and increase the nutritional value of sugar also increases the water holding capacity of surimi gel strength, and the anticold denatured protein in surimi.

\subsubsection{Interaction between Factors Affecting Gel Strength Surimi}

- Based on the response surface in Figure 11 shows that the initial rate increases, sorbitol and caragin surimi gel strength increased and then peaked in the region contour is $720 \mathrm{~g} . \mathrm{cm}$. But then if you continue to increase the proportion of blended surimi gel strength decreased. Thus, the maximum of surimi gel strength is near 720 g.cm. Conducted to detect the optimal value in this region and verifiable experiments.

-From the graph in Figure 12 shows that the initial rate increases, caragin sugar and gel strength increased. The results also show that if the graph continues to rise, the rate of sugar mixed surimi gel strength will continue to increase. But for caragin when interacting with the road, it just makes the product reaches the optimal surimi gel strength in the 740 g.cm, then if the rate continues to increase, the mix makes it surimi gel strength decreased

\section{R1}

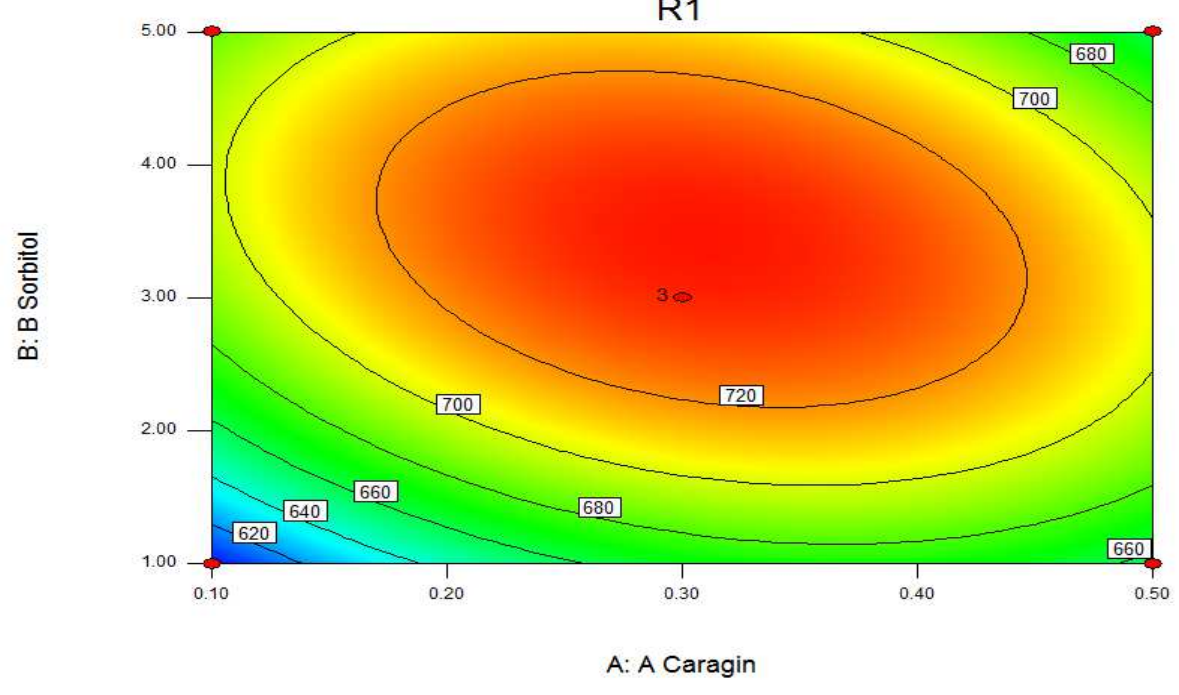

Figure 11. Effects of sorbitol to caragin and surimi gel strength 


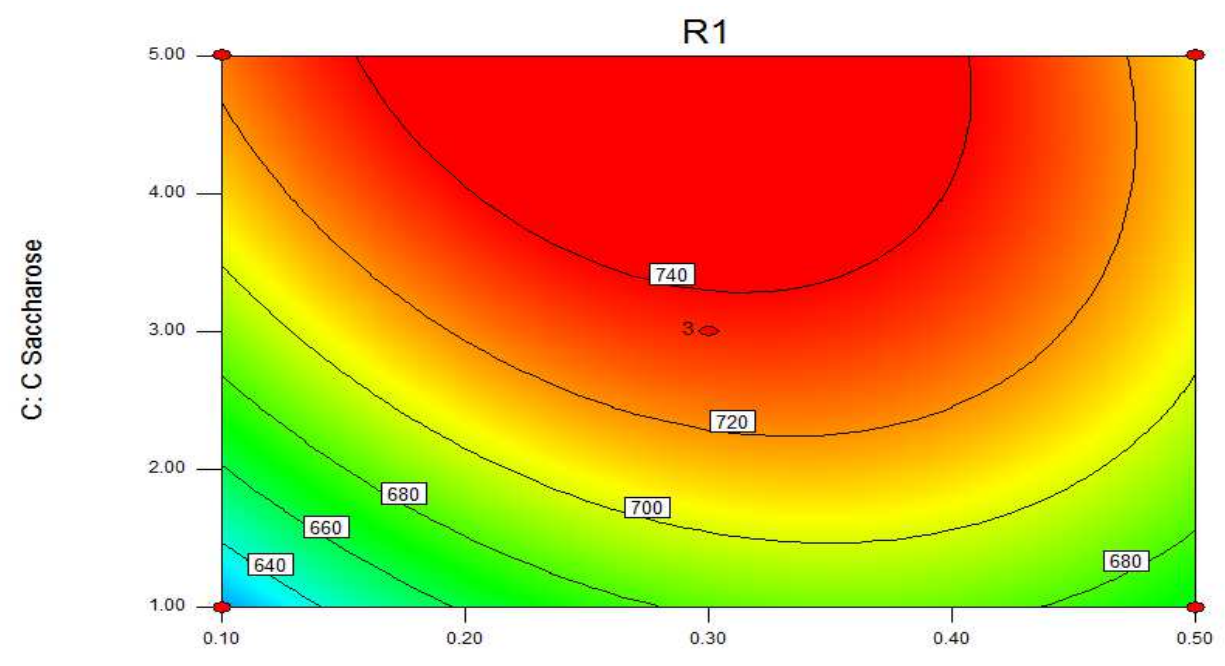

A: A Caragin

Figure 12. Effects of caragin and sugar to gel strength surimi

\subsubsection{Determining the Optimal Parameters of the Mixing Process}

Combining the three parameters of the objective function, Design-Expert 8.0 software. predicted to be an optimal number of laboratory experiments testing Conduct optimal results (Table 2) up to 3 times, taking the average results obtained surimi gel strength is roughly equivalent to 738 g.cm than predicted results.

Table 2. Optimal results predicted and experimental

\begin{tabular}{lllll}
\hline & $\begin{array}{l}\text { caragin } \\
(\%)\end{array}$ & $\begin{array}{l}\text { sorbitol } \\
(\%)\end{array}$ & $\begin{array}{l}\text { saccharose } \\
(\%)\end{array}$ & GS (g.cm) \\
\hline predict & 0,3 & 3,5 & 3,5 & 744,939 \\
Experim-ent & 0,3 & 3,5 & 3,5 & 738 \\
\hline
\end{tabular}

Thus, the optimal parameters for the process of mixing additives in surimi fish grain paint: caragin rate of $0.3 \%$, $3.5 \%$ and sorbitol rate ratio $3.5 \%$ saccharose.

\subsection{Assessing the Quality}

Conduct surimi production of paddy paint under the optimal parameters were obtained in the inspection and quality assessment, analysis results presented in Table 3.

Table 3. Results identify indicators of quality surimi products according to the process proposed

\begin{tabular}{ll}
\hline Items & Results \\
\hline I. Surimi sống & \\
1. The water content $(\%)$ & 78 \\
2. Protein $(\%)$ & 17,8 \\
3. Lipid $(\%)$ & 0,18 \\
4. The pH & 7 \\
5. Smell & Tanh rất nhẹ \\
6. Status & Mềm dẻo \\
7. Vet den/10g & 2 \\
8. Microorganisms: & \\
- The total aerobic microbial & $1,2 \times 10^{4}$ \\
- Total Coliforms & $<10$ \\
- Staphylococcus aureus & $<10$ \\
\hline
\end{tabular}

\begin{tabular}{ll}
\hline - E. coli & 0 \\
- Salmonella & 0 \\
- Vibrio & 0 \\
II. Surimi steamed & \\
1. Intensity Gel (g.cm) & 740 \\
2. Flexure moment & $\mathrm{A}$ \\
3. Smell & Very slight fishy \\
4. Status & Supple, elastic \\
5. Whiteness (\%) & 80,25 \\
\hline
\end{tabular}

\section{Conclusion}

From the above study allows to draw some conclusions as follows:

- Did research and identify optimal parameters of fish washing paint grain milling company producing surimi in Hoa Thang: 1st wash with a solution of $\mathrm{NaCl} .0,2 \%$, 2 times washing with a solution of alcohol. $2 \%$; washed 3 times with a solution sorbitol.3\%; time is 9 minutes per wash; cleaning liquid ratio than meat grinder is $4: 1$ (v/ w);

- Fully optimized and selected additives blended rate suitable for the production of surimi from fish painted grain is: sugar $3.5 \%, 3.5 \%$ sorbitol, $0.2 \%$ salt and polyphosphates caragin $0,3 \%$.

- Conducted surimi under the optimal parameters were obtained surimi choice and the Japanese standard features: 740 g.cm gel strength, whiteness and $80.25 \%$ sunspot number 2 spots / $10 \mathrm{~g}$.

Through research, we propose to continue testing fish processing surimi from other magazines follow our method parameters as a basis for process improvement surimi production in Hoa Thang Company.

\section{References}

[1] Ministry of Fisheries (1998), 28TCN119 1998. 
[2] Thailand Office Germany (2004), Study on the effect of a number of copper surimi gel quality preservation of frozen sardines in production and product testing simulated shrimp, Masters Thesis Technical University Nha Trang school.

[3] Dang Thi Thu Huong (2011), curriculum design and experimental analysis, Nha Trang University.

[4] Tran Thi Luyen (Editor), Nguyen Trong Be, Do Van Ninh, Nguyen Anh Tuan, Trang Si Trung, Vu Ngoc Boi (2010), surimi technology and simulation products, Publishers. HCMC Agriculture.

[5] Tran Thi Luyen (1996), Technical Basis and principles of processing value-added products, Volumes I, II, University of Nha Trang Fisheries.
[6] Luyen Tran Thi (1996), Research to improve the process of surimi production and processing of a number of high-end products from surimi, Synthesis Report of scientific research Ministry, College of Fisheries Home Page .

[7] Nishinari K., Watase M. (1992), Effects of sugars and polyols on the gelsoltransition of kappa-carrageenan gels// Thermochimica Acta, 206.- 149-162.

[8] Nishinari K., Watase M., Miyoshi E., Takaya T., Oakenfull D. (1995), Effects of sugar on the gel-sol transition of agarose and к-carrageenan// Food Technol. -№ 10 - 90-96.

[9] Park J., W. (2005), Surimi and Surimi Seafood, 2rd edition. CRC Press, 673-675. 